Published in "Polyhedron doi: 10.1016/j.poly.2012.08.004, 2012"

which should be cited to refer to this work.

\title{
Ring a bell: Disubstituted calix[4]arene as ligand for transition metal chlorides
}

\author{
Aurelien Crochet ${ }^{\mathrm{a}, *}$, Katharina M. Fromm ${ }^{\mathrm{a}, \mathrm{b}, *}$ \\ ${ }^{a}$ Fribourg Center for Nanomaterials (FriMat), University of Fribourg, Chemin du Musée 3, CH-1700 Fribourg, Switzerland \\ ${ }^{\mathrm{b}}$ Department of Chemistry, University of Fribourg, Chemin du Musée 9, CH-1700 Fribourg, Switzerland
}

\begin{abstract}
Lower rim 1,3-disubstituted p-tert-butylcalix[4]arene is studied here in its deprotonated form as complexing ligand for iron and chromium chloride. Crystallization of the two complexes from dry THF gives two different stoichiometries and structures, a trinuclear iron compound and a second, mononuclear structure with chromium. In both cases, the ligand adopts an elliptical shape and the metal ions are bound to the lower rim of the calixarene molecule.
\end{abstract}

\section{Introduction}

Calixarenes, in particular calix[4]arenes, are attractive molecules because of their cone-shape and the lower-rim hydroxide functions. Thus, this class of molecules can be used in many applications, e.g. as receptors for organic and inorganic analytes [1-4]. Substitution reactions [5] at the hydrophobic upper rim and the hydroxyl groups of the lower rim lead to the development of multifunctional sensors [6], capsule systems [7] and even catalytic properties [8-10]. Recent applications include also channel-type architectures for ion exchange [11], building blocks in metal organic frameworks (MOFs) [12], ion extraction [13] and antimicrobial properties [14]. Substitutions at the upper rim can lead to metal ion complexation for e.g. cross-coupling reactions [15]. The hydroxide groups at the lower rim have always been considered as good binding sites for metal ions in order to mimic oxide surface conditions and for investigating magnetism, luminescence and/or redox chemistry [16-28].

We are interested in cluster compounds, complexes and coordination polymers of alkali, alkaline earth metal and transition metal compounds in order to study their behavior in non-aqueous solvents and possible applications as catalysts and/or precursors for oxide materials [29-36]. We have previously shown that Group 2 metal halides may act as starting materials for both homo-metallic

\footnotetext{
* Corresponding authors. addresses: Fribourg Center for Nanomaterials (FriMat), University of Fribourg, Chemin du Musée 3, CH-1700 Fribourg, Switzerland (A. Crochet). Department of Chemistry, University of Fribourg, Chemin du Musée 9, CH1700 Fribourg, Switzerland (K.M. Fromm).

E-mail addresses: aurelien.crochet@unifr.ch (A. Crochet), katharina.fromm@ unifr.ch (K.M. Fromm).
}

alkaline earth and mixed-metal alkali and alkaline earth metal cage compounds obtained from partial abstraction of halide [3741]. Depending of the bulk of the R group on the alkoxide or aryloxide reagent and the nature of the alkali metal and the solvent of crystallization (binding mode, Lewis basicity, and so forth), different structural features can be achieved $[29,42,43]$. In this context, we have also studied calixarenes, which can be understood as cyclic polyphenols. Deprotonated with an organo-lithium compound, the formed compounds can be considered as lithium polyaryloxides [44-46]. The sensitivity of such aryloxide complexes, including deprotonated calixarenes, to moisture is always described as a disadvantage for this family of complexes, which are difficult to handle, store, and analyze.

In previous work, we have synthesized deprotonated alkali calixarenes [46]. One of them (Fig. S1) is obtained by addition of lithium tert-butyloxide in THF-solution to a suspension of $p$ tert-butylcalix[4]arene in dry THF. In order to avoid dimerization or oligomerization, we have chosen to limit the quantity of labile protons on the $p$-tert-butylcalix[4]arene. We have thus replaced two hydroxyl groups by two methyl ether groups (Scheme 1) as these are short and thus reduce the impact of their presence on the complexation sites (least possible change in the electronegativity and least bulky as possible in order to have an easy access to the oxygen atoms for metal ions). For the synthesis of 1,3-dimethylp-tert-butylcalix[4]arene, $\mathbf{H}_{2} \mathbf{L}$, we used a method described by Huang and co-workers (Scheme 1) [47].

1,3-Dimethyl-p-tert-butylcalix[4]arene can be deprotonated by several different methods: with sodium [48], sodium hydride [49,50], mesityllithium [51], butyllithium [49,52], potassium [49], potassium bis(trimethylsilylamide) [53], rubidium [49], or even cesium [49]. In 1997, Dubberley et al. published the dimeric structure 

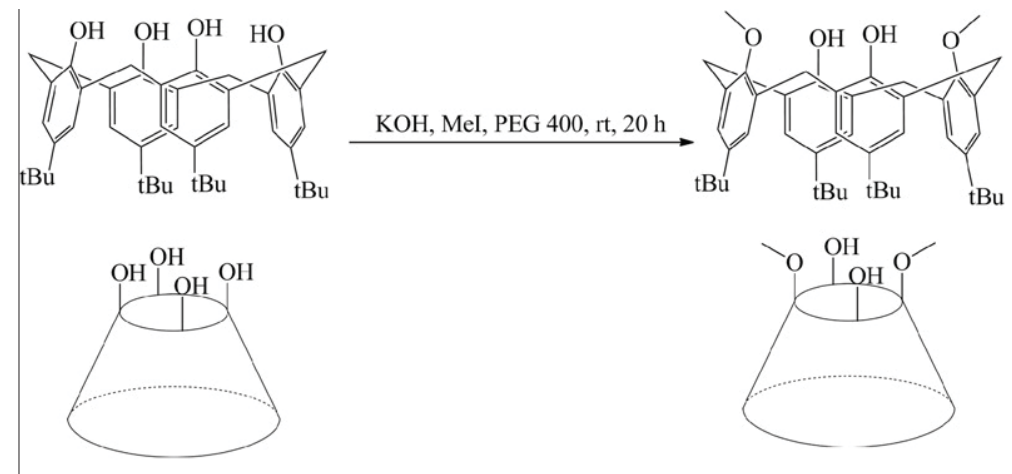

$\mathrm{H}_{2} \mathrm{~L}$

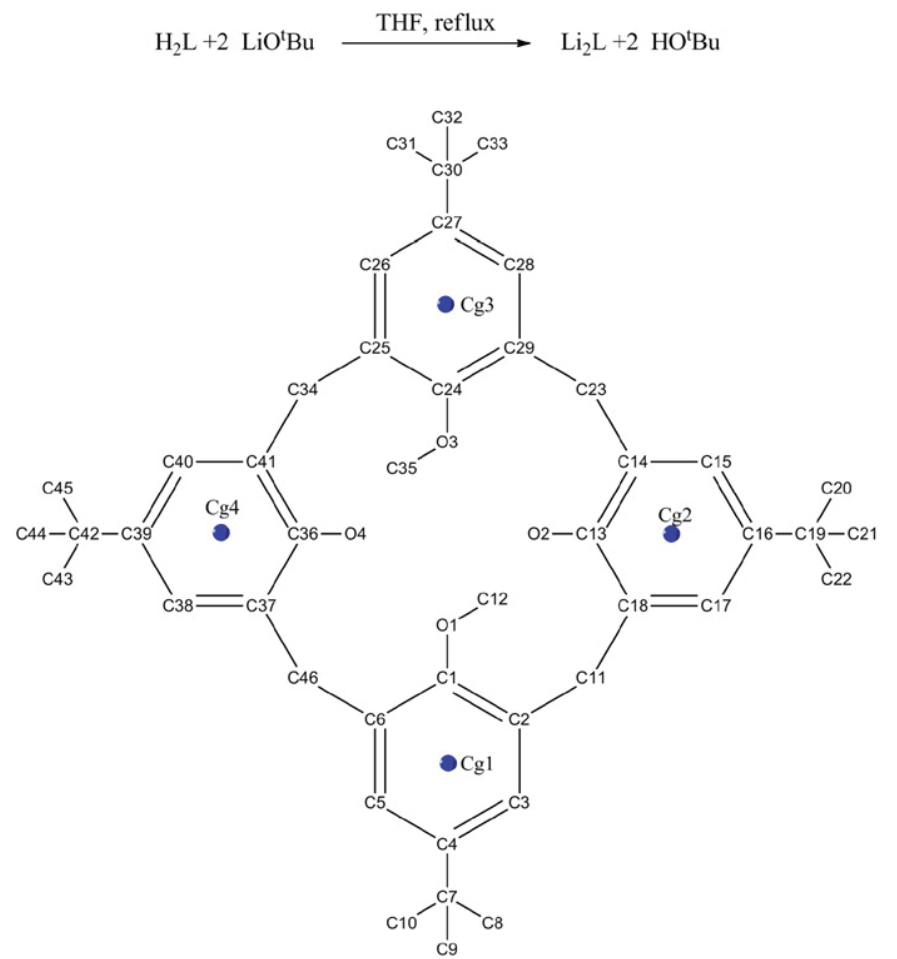

Scheme 1. Scheme of the alkylation (top), the deprotonation (middle) and the numbering of atoms of deprotonated calix[4]arene ligand $\mathbf{L}^{\mathbf{2}}$.

of the sodium dimethylcalix salt [50], and in 2003, he published two forms of the lithium salt, a dimeric one and one monomeric form, as established by spectroscopic analyses [49]. We produced the lithiated calixarene by reaction with two equivalents of lithium tert-butyloxide, this compound is noted $\mathbf{L i}_{\mathbf{2}} \mathbf{L}$ (Scheme 1). This lithiated ligand will be used as reagent for iron and chromium halide in order to obtain new (mixed) metal complexes. As driving force for the transition ion complexation by the calix[4]arene ligand, we will make use of the elimination of $\mathrm{LiCl}$. In first reaction, this is tested for $\mathrm{FeCl}_{2}$ as this fits well with the two lithium ions of $\mathbf{L i}_{2} \mathbf{L}$ and should thus yield an iron complex. All reactions are carried out under inert atmosphere and using dried solvents.

\section{Results and discussion}

2.1. The iron complex $\left[\mathrm{Li}(\mathrm{THF})_{4}\right]\left[\mathrm{Fe}_{3} \mathrm{Cl}_{5}(\mathbf{L})(\mathrm{THF})\right](\mathbf{1})$

The first compound, [Li(THF) $\left.)_{4}\right]\left[\mathrm{Fe}_{3} \mathrm{Cl}_{5}(\mathbf{L})(\mathrm{THF})\right]$ (1) (Scheme 2), was obtained via addition of dry iron(II) chloride to a THF-solution of $\mathbf{L i}_{\mathbf{2}} \mathbf{L}$. The compound crystallizes in the monoclinic space group $P 2_{1} / n$ (No. 14) (Fig. 1). The structure is composed of two units,

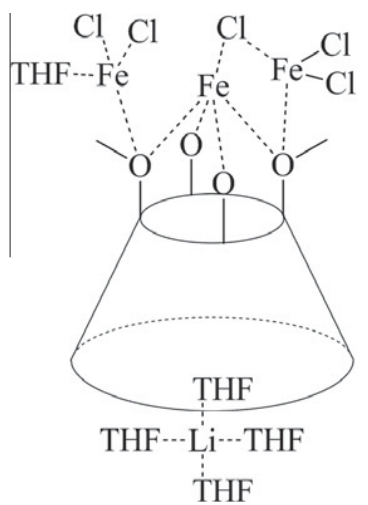

Scheme 2. Schematic representation of (1).

one cationic which consists of lithium surrounded by four THF molecules, and one anionic unit A composed of one functionalized calixarene, three iron ions, five chloride anions and one THF molecule (Fig. 1). Unit A contains the three Fe(III) ions, which each have 


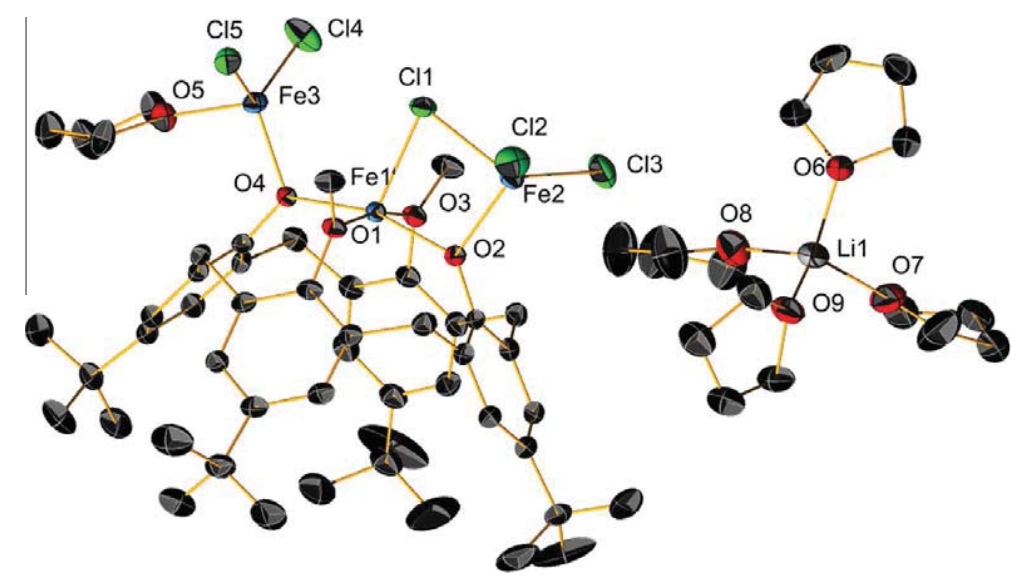

Fig. 1. Molecular view of 1, 35\% of probability, $\mathrm{H}$ atoms are omitted for clarity.

different coordination spheres. Fe1 is pentacoordinated and bound to the four oxygen atoms (Fe1-01 2.168(3) $\AA$, Fe1-O2 1.955(2) $\mathrm{A}$, Fe1-O3 2.160(3) A, Fe1-O4 1.967(23) $\AA$ ) of the phenol moieties of the ligand in an almost square planar fashion (Fe1-plane $\{01$, O2, O3, O4 $0.247 \AA$ ). It is capped by a chloride ion Cl1 in apical position (2.391(1) A), pointing away from the calixarene moiety. The two other iron ions are tetracoordinated. Fe2 binds to the calixarene via $\mathrm{O} 2(2.049(2) \AA)$ and to three chloride ions $\mathrm{Cl} 1$ (2.433(1) $\AA$ ), $\mathrm{Cl} 2$ (2.256(1) $\mathrm{A}$ ) and $\mathrm{Cl} 3$ (2.241(2) $\mathrm{A}) . \mathrm{Cl} 1$ acts thus as bridging ligand for $\mathrm{Fe} 1$ and $\mathrm{Fe} 2$. The third ion, Fe3, is connected to $\mathrm{O} 4(2.021(2) \AA), \mathrm{Cl} 4(2.249(1) \AA)$ and $\mathrm{Cl} 5$ (2.280(1) $\AA$ ). Its coordination is completed by one THF molecule (Fe3-05 2.083(3) $\AA$ ).

For Fe1, a five-coordination is observed. To evaluate between a trigonal bipyramid or a square pyramidal, an evaluation of the structural index parameter can be made. This parameter was introduced by Addisson et al. [54]. We have previously applied this method for a mercury(II) iodide dibenzo-24-crown-8 complex [32]. In this model, the metal $\mathrm{M}$ is coordinated by the five atoms A, B, C, D and E, as shown in Scheme 3 below. In a square-pyramidal geometry, one would have $\alpha=\beta=180^{\circ}$ with A as the axial ligand (Scheme 3 ). In most real square pyramidal environments however, the metal ion $\mathrm{M}$ is shifted towards $\mathrm{A}$, such that both angles are $<180^{\circ}$, with $\beta$ being the largest of the basal angles (B-M-C in Scheme 3 left) and $\alpha$ the smallest (D-M-E in Scheme 3). For trigonal bipyramidal structures, $\alpha$ is $120^{\circ}$ with B-M-C as principle axis. In compound 1 the angles are $\beta=01-\mathrm{Fe} 1-03$ 169.47(9) and $\alpha=02-\mathrm{Fe} 1-04=162.4(1)^{\circ}$.

The geometric parameter $\tau=(\beta-\alpha) / 60$ "which is applicable to five coordinated structures as an index of the degree of the trigonality, within the structural continuum between trigonal bipyramidal and rectangular pyramidal. For a perfectly tetragonal geometry $\tau$ is equal to zero, while it becomes unity for perfectly trigonal bipyramidal geometry" [54]. Application of this parameter to our compound $\mathbf{1}$ gives a value of 0.12 which indicates a geometry clearly nearest a square pyramidal rather than trigonal bipyramidal geometry [55].
The distances between the iron ions of 3.1085(7) Å for Fe1-Fe2 and 3.3548(7) Å for Fe1-Fe3, are too long to consider metal-metal bonds. In order to determine the oxidation states of the iron ions, the Bond Valence Sum (BVS) method is applied [56,57]. The values found are 2.12 for Fe1, 1.99 for Fe2 and 2.00 for Fe3, confirming that we are in the presence of three iron (II) ions.

The packing view shows that one of the THF molecules of the $\left[\mathrm{Li}(\mathrm{THF})_{4}\right]^{+}$cationic moiety penetrates into the hydrophobic cavity at the upper rim of the calix[4]arene ligand L. This THF is connected via $\mathrm{H}$-bonding with the aromatic rings of the calix[4]arene ligand (Fig. 2).

For compound 1, the strategy of substitution of two hydroxide functions for two methoxy groups successfully leads to the formation of monomeric complexes with respect to the calixarene ligand. The three iron atoms are asymmetrically coordinated in the solid state. However, in solution, a certain dynamic exchange can occur as exemplified in Scheme 4. THF is then a labile ligand, which can easily leave the iron ion to which it is coordinated, with the central chloride atom $\mathrm{Cl} 1$ providing the missing electron pair for the metal ion (intermediate bottom Scheme 4). Upon recoordination, THF can then bind to both outer iron atoms with the same probability, as the intermediate is symmetric. This would then give to the complex dynamism in solution.

According to the literature [58-61], surface covered of $\mathrm{FeCl}_{2}$ [62,63], respectively pentacoordinated Fe(II) complexes [64] can be used as catalyst for polymerization processes. Compound $\mathbf{1}$ might thus be a potential catalyst as (i) the THF-ligand on $\mathrm{Fe} 2$ might be labile in solution and would free a coordination site on the metal ion, and (ii) Fe1 has a free coordination site located inside the calixarene ligand.

In order to verify if compound $\mathbf{1}$ has some catalytic properties, a small amount of it was mixed with a solution of styrene in a mixture of THF/DCM. In our hands, no conversion of styrene to polystyrene was observed, thus, the complex does not possess catalytic properties in this context. Smaller monomers did also not yield
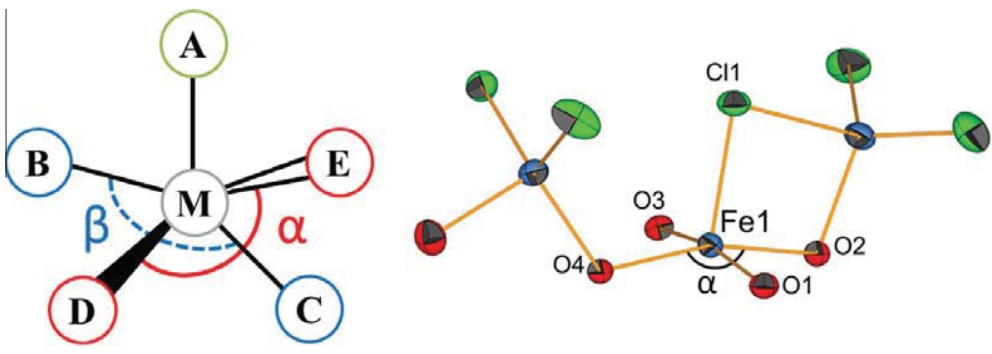

Scheme 3. Determination of the structural index parameter for compound $\mathbf{1}$. 

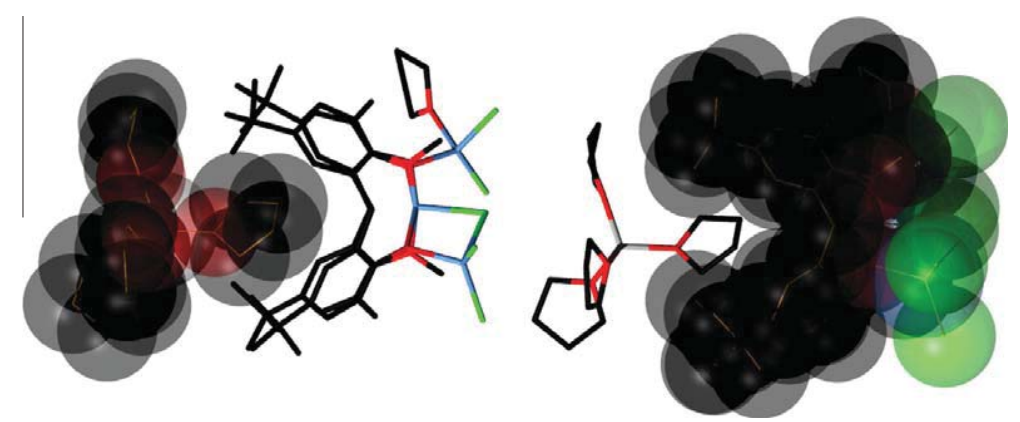

Fig. 2. Molecular view of 1; H atoms are omitted for clarity. The two variants show the penetration of a THF molecule of the cation into the calix[4]arene moiety.

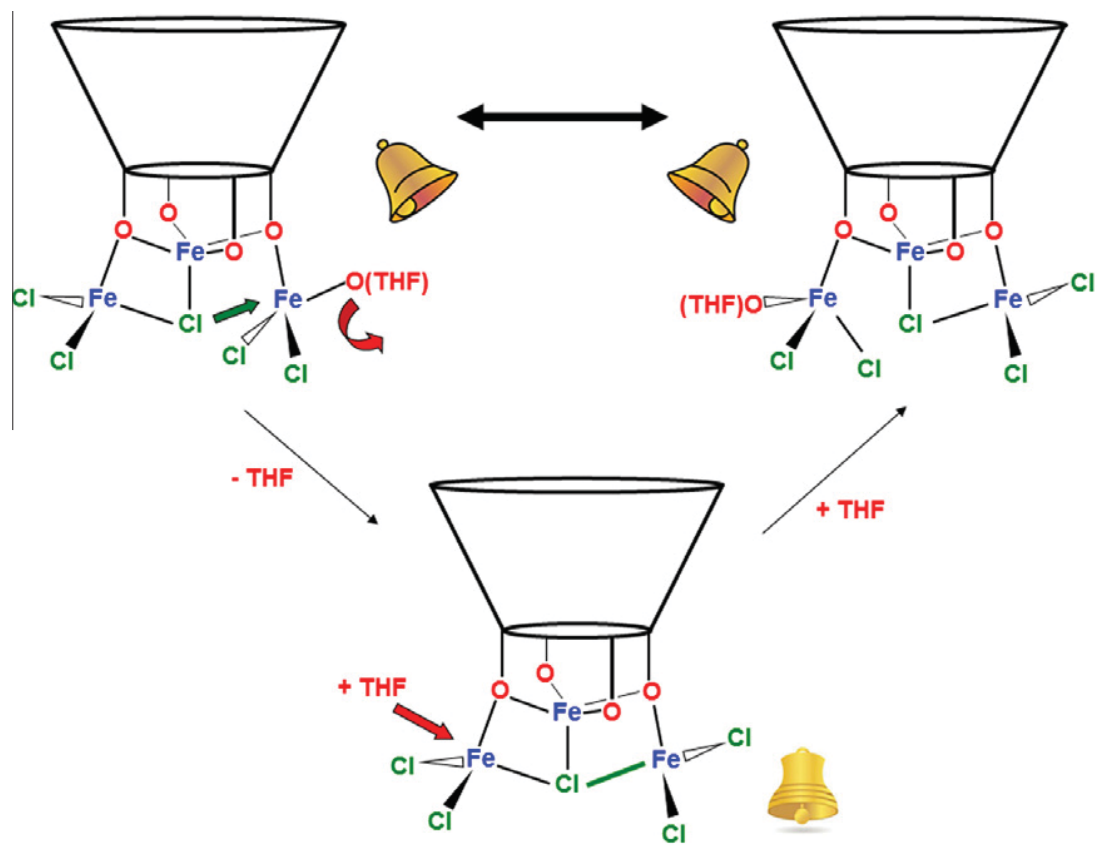

Scheme 4. Ringing the "iron bell" with the central chloride ion.

polymers in presence of $\mathbf{1}$. This might be due to the fact that no free coordination site is accessible at the iron ions $\mathrm{Fe} 2$ and $\mathrm{Fe} 3$ if our intermediate, postulated in Scheme 4 forms. Also, the free coordination site on $\mathrm{Fe} 1$ is difficult to access as the substrate would have to enter the calixarene cavity. There would, if at all, not be enough space to accommodate one or two monomers in order to connect them. Unfortunately, we could not verify this hypothesis of reactivity in solution by NMR as it gave only very broad, shifted signals.

In the literature, only four structures were found, in which two hydroxyl groups are protected by methanol or benzyl alcohol and among these four structures only one contains iron(II) $[16,65,66]$. In all these publications, the calixarene ligand is coordinated to only one iron ion. Our compound is thus, to the best of our knowledge, the first calixarene complex coordinating with three iron(II) ions and exposing a $\mathrm{FeCl}_{2}$-face.

\subsection{Chromium complex, $\left[\mathrm{CrCl}_{2}(\mathrm{~L}) \mathrm{Li}(\mathrm{THF})\right], 4 \mathrm{THF}(2)$}

The compound $\left[\mathrm{CrCl}_{2}(\mathrm{~L}) \mathrm{Li}(\mathrm{THF})\right]$, 4THF (2), was obtained by addition of one equivalent of chromium(II) chloride to a solution of $\mathbf{L i}_{\mathbf{2}} \mathbf{L}$ in dry THF. The compound crystallizes in the triclinic space group $P \overline{1}$ (No. 2) (Scheme 5 and Fig. 3 ). The structure consists of one chromium ion connected to the four oxygen atoms of the calixarene ligand, with $\mathrm{O} 1$ and $\mathrm{O} 3$ methylated (Cr1-O1 2.038(2) Å;

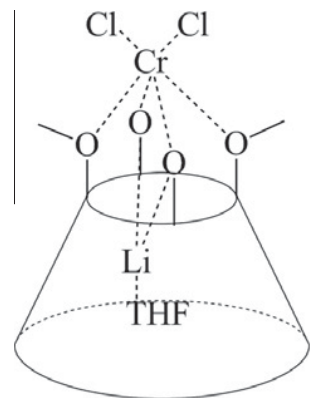

Scheme 5. Schematic representation of (2).

Cr1-O3 2.036(2) $\AA$ ) and $\mathrm{O} 2$ and $\mathrm{O} 4$ deprotonated (Cr1-O2 1.939(3) $\AA$ and $\mathrm{Cr} 1-\mathrm{O} 41.907(2) \AA)$. The coordination sphere of the chromium ion is completed by two chloride ions $\mathrm{Cl} 1$ and $\mathrm{Cl} 2$ (Cr1-Cl1 2.308(1) Å and Cr1-Cl2 2.299(1) $\AA$ ), leading to a slightly distorted octahedron around the metal ion, with $\mathrm{Cl} 1-\mathrm{Cr} 1-\mathrm{Cl} 2$ 95.22(4) ${ }^{\circ}, 01-\mathrm{Cr} 1-0382.5(4)^{\circ}$ and $02-\mathrm{Cr} 1-04$ 171.1(1) ${ }^{\circ}$ (Fig. 3).

The two hydroxide oxygen atoms $\mathrm{O} 2$ and $\mathrm{O} 4$ are coordinating to a lithium ion Li1 (Li1-O2 1.854(8) ̊ and Li1-O4 1.84(1) Å, which has its coordination sphere completed by one THF molecule Li105 1.896(9) Å. This trigonal planar lithium cation (angle sum of 


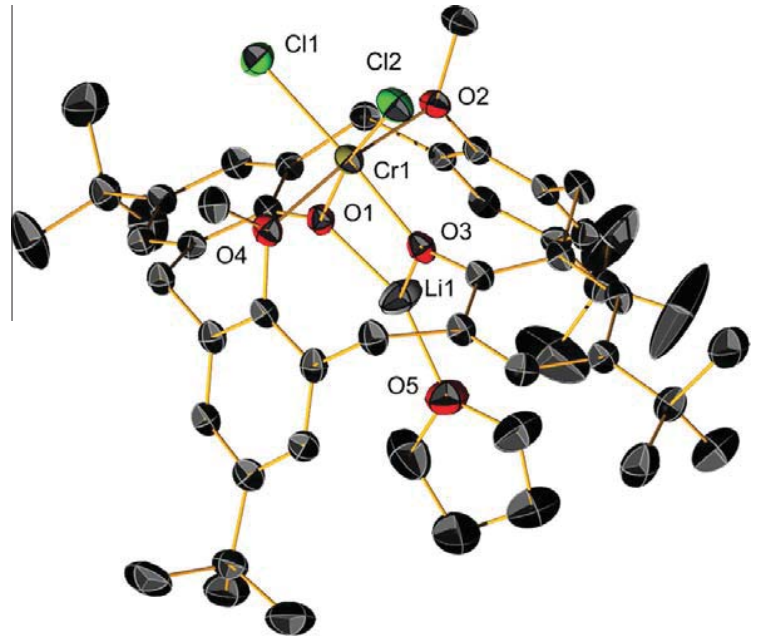

Fig. 3. Molecular view of 2; $\mathrm{H}$ atoms and free THF molecules omitted for clarity, $25 \%$ of probability.

Table 1

Comparison between two $\mathrm{Cr}$ (III) calix complexes.

\begin{tabular}{lll}
\hline & R $[23]$ & $\mathbf{2}$ \\
\hline $\mathrm{PhO}-\mathrm{Cr}(\AA)$ & $1.919(1) ; 1.922(1)$ & $1.939(3) ; 1.907(2)$ \\
$\mathrm{PhO}-\mathrm{Cr}-\mathrm{OPh}\left({ }^{\circ}\right)$ & $78.90(6)$ & $78.7(1)$ \\
$\mathrm{PhO}(\mathrm{Me})-\mathrm{Cr}(\AA)$ & $2.038(2) ; 2.047(2)$ & $2.036(2) ; 2.038(2)$ \\
$\mathrm{PhO}(\mathrm{Me})-\mathrm{Cr}-(\mathrm{Me}) \mathrm{OPh}\left(^{\circ}\right)$ & $172.01(6)$ & $171.1(1)$ \\
$\mathrm{Cr}-\mathrm{Cl}(\AA)$ & $2.3165(6) ; 2.3159(6)$ & $2.299(1) ; 2.308(1)$ \\
$\mathrm{Cl}-\mathrm{Cr}-\mathrm{Cl}\left({ }^{\circ}\right)$ & $94.68(6)$ & $95.22(4)$ \\
$\mathrm{PhO}-\mathrm{Li}(\AA)$ & $1.954(4) ; 1.994(4)$ & $1.84(1) ; 1.854(8)$ \\
$\mathrm{PhO}-\mathrm{Li}-\mathrm{OPh}\left(^{\circ}\right)$ & $76.4(2)$ & $82.5(4)$ \\
$\mathrm{BVS}(\mathrm{Li})$ & 0.90 & 1.02 \\
Angle between plan $\mathrm{OPh}\left({ }^{\circ}\right)$ & 161 & 151 \\
Angle between plan $\mathrm{MeOPh}\left({ }^{\circ}\right)$ & 41 & 54 \\
\hline
\end{tabular}

$357.17^{\circ}$ ) has a Bond Valence Sum (BVS) of 1.02 and sits in the cavity of the calixarene. It forms also interactions with the $\pi$-systems of two phenyl rings: The distance between the centroïd of the ring connected to $\mathrm{O} 1(\mathrm{Cg} 1)$ and Li1 is ca. $2.97 \AA$ and between $\mathrm{Cg} 3$ and Li1 ca. 3.42 Å (Cg1-Li1-Cg3 173.38 $)$.

The BVS value of the chromium ion is 3.12 , which assumes an oxidation state of three, thus an oxidation of $\mathrm{Cr}$ (II) to $\mathrm{Cr}$ (III) occurred. One possibility for this oxidation can be the formation of radicals in THF solution. These radicals can be transferred to deprotonated calixarene and eliminated by oxidation of the chromium(II) ion. Indeed Giese has studied this phenomenon of radical formation in a calix[4]arene, in order to identify the position of the radical as a function of the protonation of the phenol group. Calculations and measurements show that if a radical is formed on the calixarene, it will rather go to the oxygen atom of the alcohol than to the $\mathrm{CH}_{2}$-group [67]. The elimination of this radical on the oxygen atom of a deprotonated calix[4]arene seems then to be sufficient to oxidize the chromium(II) to chromium(III).

In 2000, Hesschenbrouck et al. published a structure of chromium(III) chloride with dimethylcalix[4]arene [51]. In this complex, chromium(III) is hexacoordinated by four oxygen atoms of the calixarene ligand, one chloride ion and one THF molecule. This complex does not have additional lithium in the structure. In 2009, Redshaw et al. published a similar structure to $\mathbf{2}$ [23]. The difference (Table 1) between Redshaw's compound and ours resides mainly in the coordinating solvent. In Redshaw's structure (R), the lithium ion is tetracoordinated (by two oxygen atoms of the calixarene ligand and by two acetonitrile molecules).

\subsection{General remark on the ligand: opening of the calix[4]arene}

Comparing the angle between the planes containing the deprotonated phenol moieties with the one between planes containing the methylated phenol groups, we remark that we are in presence of elliptical conical frustum scheme and not circular conical frustum. Indeed, in compound 1, planes containing $\mathrm{PhO}^{-}$form an angle of around $69^{\circ}$ and planes containing PhOMe are inclined against each other by ca. $49^{\circ}$. In compound 2 , these angles are ca. $151^{\circ}$ and $54^{\circ}$ respectively. Thus, the calixarene ligand of $\mathbf{2}$ is much flatter than in 1. Distances between the central carbon atom of the tert-butyl group are also good indicators: 9.271(7) A for the methylated groups and 10.622(6) $\AA$ for the $\mathrm{PhO}^{-}$-moieties in $\mathbf{1}$, and 9.269(5) $\AA$ and 13.406(6) $\AA$, respectively, in 2. This opening of the calixarene is common with dimethylcalix[4]arene and is more pronounced when a metal ion is coordinated endo in the calixarene cavity (Fig. S4) [16,23,51,52,65,66,68-72].

The ligand alone adopts the cone conformation while in principle, many other are possible for a calix[4]arene [74,75]. Only four crystal structures of $\mathbf{H}_{\mathbf{2}} \mathbf{L}$ are published, one with an empty cavity [73], two with solvent in the cavity (toluene [70] or acetonitrile [74]) and one structure in which one empty calixarene adopts a 1,2-alternate conformation and a second one a cone conformation with acetonitrile in the cavity [74]. In case of the cone conformation with an empty cavity, the aromatic rings opposite to each other form angles of ca. $8^{\circ}$ and $63^{\circ}$ for the methoxy-substituted, respectively hydroxy-substituted rings. Presence of solvent in the cavity slightly increases these angles to $39^{\circ}$ and $89^{\circ}$ in case of toluene and in case of acetonitrile to around $41^{\circ}$ and $71^{\circ}$ or $43^{\circ}$ and $74^{\circ}$ depending of the structure (Table 2 ). Solvent alone does thus not have a so big impact on the cavity opening compared to calixarene when used as ligand for transition metal ions (see Fig. S5). Indeed, in $\mathbf{1}$ the calixarene cavity is empty except for the $[\mathrm{Li}(\mathrm{THF})]^{4+}$ cation pointing into the cavity and forming $\mathrm{C}-\mathrm{H} . . . \pi$ (2.5-3.2 $\AA$ ) interactions. This leads to a more or less spherical cone conformation with a slight enlargement of this corresponding angle versus the other (see Table 2). However, in compound $\mathbf{2}$, the calixarene ligand adopts a flatter conformation than in $\mathbf{1}$ due to

Table 2

Comparison of angles for the methoxy- and the hydroxy-substituted rings

\begin{tabular}{|c|c|c|c|c|c|}
\hline Calix[4]arene & Cavity & For MeOPh plans $\left(^{\circ}\right)$ & For $(\mathrm{H}) \mathrm{OPh}$ plans $\left(^{\circ}\right)$ & $\mathrm{C}-\mathrm{C}$ for $\mathrm{MeOPh}$ & $\mathrm{C}-\mathrm{C}$ for $(\mathrm{H}) \mathrm{OPh}$ \\
\hline \multirow[t]{7}{*}{ Dimethyl } & Empty [73] & 8 & 63 & $6.041(6)$ & $12.667(6)$ \\
\hline & Toluene [70] & 39 & 89 & $10.010(7)$ & $11.415(8)$ \\
\hline & Acetonitrile [74] & 41 & 71 & $8.615(4)$ & $10.213(4)$ \\
\hline & Acetonitrile [74] & 43 & 75 & $8.462(3)$ & $10.466(3)$ \\
\hline & $\operatorname{THF}(\mathbf{1})$ & 49 & 69 & $9.271(7)$ & $10.622(6)$ \\
\hline & Li-THF (2) & 54 & 151 & $9.269(5)$ & $13.406(6)$ \\
\hline & $\mathbf{R}[23]$ & 41 & 161 & $8.223(5)$ & $13.638(8)$ \\
\hline \multirow[t]{2}{*}{ Nonsubstituted } & Half-lithiated (THF) [46] & 62 & 71 & $9.797(5)$ & $10.543(4)$ \\
\hline & Fully lithiated (Li-THF) [46] & 34 & 79 & $8.539(5)$ & $11.760(6)$ \\
\hline
\end{tabular}


the endo binding of the lithium cation. This resembles the effect observed in the fully lithiated calix[4]arene [46], where also one lithium ion is included in the cone cavity (Fig. S1), and to which one THF ligand is bound. Thus, the presence of complexed transition metal ion(s) at the lower rim and lithium complexation inside the cavity increase the ring opening with an enlargement between the hydroxy-substituted rings.

\section{Conclusions}

In conclusion, the difunctionalization of the calix[4]arene at the lower rim hydroxy groups has provided the formation of monomeric species as expected. The formation of complexes with the lithiated calixarene has been realized with two different metal halides: $\mathrm{FeCl}_{2}$ and $\mathrm{CrCl}_{2}$. In the case of $\mathrm{FeCl}_{2}$, by adding excess of metal salt, we have obtained a trinuclear complex in which the iron ions have two different coordination geometries, tetrahedral and square pyramidal. All three iron ions possess different coordination spheres. In our hands, this compound did now show any catalytic effect which can be explained by the good donor properties of the central chloride ion. In the case of $\mathrm{CrCl}_{2}$, we have obtained a mononuclear chromium(III) complex, obtained after oxidation of the metal ion. The presence of an endo-bound lithium ion in the cavity of the calixarene leads to a flat cone conformation of the ligand in compound 2.

\section{Experimental}

All experiments were carried out under an inert argon atmosphere, using Schlenk technique [76]. THF was dried in drying unit under argon and stocked on molecular sieve; other solvents were bought dried and stocked on molecular sieve. The BVS calculations are performed with valist [77]. For single-crystal measurements, a Stoe IPDS II theta, equipped with monochromated Mo K $\alpha$ radiation $(0.71073 \AA$ ) . IR and NMR spectra were recorded on a Bruker Tensor 27 and on a Bruker AM360, respectively.

4.1. $\left[\mathrm{Li}_{2}\left(\operatorname{calix}(\mathrm{OMe})_{2}\right)\right] \mathbf{L i}_{\mathbf{2}} \mathbf{L}$ : First part: synthesis of dimethyl-p-tertbutylcalix[4]arene [47]

\subsubsection{First part: methylation $\boldsymbol{H}_{2} \boldsymbol{L}$}

p-tert-Butylcalix[4]arene $(1.62 \mathrm{~g}, 2.5 \mathrm{mmol})$ was dissolved in $30 \mathrm{~mL}$ chloroform. $\mathrm{KOH}$ ( $20 \mathrm{mmol}, 1.12 \mathrm{~g}$ ) was dissolved in $20 \mathrm{~mL}$ water and added to the calixarene solution. $\mathrm{MeI}(4.25 \mathrm{~g}, 30 \mathrm{mmol})$ and PEG 400 (5 g) were added and left under magnetic stirring during $20 \mathrm{~h}$. Afterwards the solution was neutralized with $\mathrm{HCl}$ and extracted with chloroform. Most of the solvent was removed by vacuum and methanol was added for crystallization. After $12 \mathrm{~h}$, white crystals were obtained with a yield of $90 \% .{ }^{1} \mathrm{H} \mathrm{NMR}\left(\mathrm{CDCl}_{3}\right.$, $360 \mathrm{MHz}$ ): 7.16 (s, 2H, OH), $7.02(\mathrm{~s}, 4 \mathrm{H}), 6.72$ (s, 4H, Ar-H), 4.27 (d, $\left.4 \mathrm{H}, \mathrm{ArCH}_{2} \mathrm{Ar}\right), 1.30\left(\mathrm{~s}, 18 \mathrm{H}, \mathrm{C}\left(\mathrm{CH}_{3}\right)_{3}\right), 3.90\left(\mathrm{~s}, 6 \mathrm{H}, \mathrm{CH}_{3}\right) . \mathrm{IR}$ : $3444 \mathrm{~cm}^{-1}(\mathrm{w}), 2952(\mathrm{~m}), 2906(\mathrm{sh}), 2869(\mathrm{sh}), 1601(\mathrm{sh}), 1479(\mathrm{~m})$, 1482(s), 1435(sh), 1360(sh), 1326(s), 1303(sh), 1202(m), 1167(m), 1125(m), 1091(m), 1023(sh), 989(sh), 870(m), 796(s), 691(s), 531(m).

\subsubsection{Second part: deprotonation}

Dimethyl-p-tert-butylcalix[4]arene $\left(\mathbf{H}_{2} \mathbf{L}\right)(1.52 \mathrm{~g}, 2.25 \mathrm{mmol})$ was dried under vacuum for $2 \mathrm{~h}$ under vacuum at $150^{\circ} \mathrm{C}$, dissolved in $30 \mathrm{~mL} \mathrm{THF}$, and heated to reflux under magnetic stirring during $1 \mathrm{~h} .4 .5 \mathrm{~mL}$ ( 2 equiv) of a solution of lithium tert-butyloxide $1.0 \mathrm{M}$ in THF was added slowly to the suspension and the mixture became clear. The solution was filtered and evaporated to dryness to give of yield of 95\%. ${ }^{1} \mathrm{H}$ NMR (THF-d8, $360 \mathrm{MHz}$ ): 6.93 (b, 4H,
Ar-H), 6.68 (b, 4H, Ar-H), 4.28 (b, 8H, ArCH $\mathrm{Ar}), 1.27$ (s, 36H, $\left.\mathrm{C}\left(\mathrm{CH}_{3}\right)_{3}\right), 3.93\left(\mathrm{~s}, 6 \mathrm{H}, \mathrm{CH}_{3}\right)$. IR: $2953 \mathrm{~cm}^{-1}(\mathrm{~m}), 2925(\mathrm{sh}), 2860(\mathrm{sh})$, 1601(sh), 1479(m), 1482(s), 1435(sh), 1360(sh), 1326(s), 1303(sh), 1202(m), 1167(m), 1125(m), 1091(m), 1023(sh), 989(sh), 870(m), 796(s), 691(s), 531(m).

$\left[\mathrm{Li}(\mathrm{THF})_{4}\right]\left[\mathrm{Fe}_{3} \mathrm{Cl}_{5}\left(\mathrm{Calix}(\mathrm{OMe})_{2}\right)(\mathrm{THF})\right] \mathbf{1}: \mathbf{L i}_{2} \mathbf{L}$ (synthesized from $1.62 \mathrm{~g}, 2.5 \mathrm{mmol}$ of $p$-tert-butylcalix[4]arene) in THF solution was added to $\mathrm{FeCl}_{2}(2 \mathrm{~g}, 16 \mathrm{mmol})$. The mixture was heated to reflux under magnetic stirring during $30 \mathrm{~min}$. The solution was filtrated, concentrated and $20 \mathrm{~mL}$ of heptane were added, the mixture was left at room temperature. Brown single-crystals of $\mathbf{2}$ suitable for $\mathrm{X}$-ray analysis grow after some weeks with a yield of ca. $80 \%$. IR: $2952 \mathrm{~cm}^{-1}(\mathrm{~m}), 2918(\mathrm{~s}), 2865(\mathrm{sh}), 1609(\mathrm{sh}), 1458(\mathrm{~m}), 1392(\mathrm{~s})$, 1360(sh), 1297(s), 1255(s), 1199(m), 1093(sh), 1028(sh), 909(s), 870(m), 849(m), 822(s),797(s), 747(s).

$\left[\mathrm{CrCl}_{2}\left(\mathrm{Calix}(\mathrm{OMe})_{2}\right) \mathrm{Li}(\mathrm{THF})\right]$, 4THF $\mathbf{2 :} \mathbf{L i}_{\mathbf{2}} \mathbf{L}$ (synthesized from $1.62 \mathrm{~g}, 2.5 \mathrm{mmol}$ of $p$-tert-butylcalix[4]arene) was dissolved in THF and was added to $\mathrm{CrCl}_{2}(2 \mathrm{~g}, 16.4 \mathrm{mmol})$. The mixture was heated to reflux under magnetic stirring during $30 \mathrm{~min}$. The solution was filtrated, concentrated and $20 \mathrm{~mL}$ of heptane were added. The mixture was left at room temperature. Green single-crystals of 2 suitable for X-ray analysis grow after some weeks with a yield of 30\%. IR $2952 \mathrm{~cm}^{-1}(\mathrm{~m}), 2925(\mathrm{~s}), 2856(\mathrm{sh}), 1595(\mathrm{sh}), 1476(\mathrm{~m})$, 1459(sh), 1361(sh), 1342(sh), 1316(m), 1028(w), 1162(sh), 1093(sh), 1040(m), 1017(m), 917(sh), 860(m), 805(sh), 773(sh), 762(s), 713(sh), 688(m).

\subsection{X-ray analysis}

Single crystal X-ray structure determination: crystals were mounted on loops and all geometric and intensity data were taken from this crystal. Data collection took place using Mo K $\alpha$ radiation $(\lambda=0.71073 \AA$ ). Measurements were performed at $200 \mathrm{~K}$ on a STOE IPDS-II theta diffractometer equipped with an Oxford Cryosystem open flow cryostat [78]. Absorption correction was partially integrated in the data reduction procedure [79]. The structures were solved and refined using full-matrix least-squares on $F^{2}$ with the SHELX-97 package [80]. All heavy atoms could be refined anisotropically. Hydrogen atoms were introduced as fixed contributors when a residual electronic density was observed near their expected positions. In compound $\mathbf{2}$, four tetrahydrofuran solvates molecule were accounted for by using the program PLATON/SQUEEZE [55]. Crystallographic table are available in the Supplementary material (Table S1).

\section{Acknowledgments}

The authors thank the Swiss National Science Foundation as well as the Fribourg Center for Nanomaterials (FriMat) for most generous support.

\section{Appendix A. Supplementary data}

CCDC 884409 and 884410 contain the supplementary crystallographic data for $\mathbf{1}$ and 2, respectively. These data can be obtained free of charge via http://www.ccdc.cam.ac.uk/conts/retrieving.html, or from the Cambridge Crystallographic Data Centre, 12 Union Road, Cambridge CB2 1EZ, UK; fax: (+44) 1223-336-033; or e-mail: deposit@ccdc.cam.ac.uk. Supplementary data associated with this article can be found, in the online version, at http:// dx.doi.org/10.1016/j.poly.2012.08.004.

\section{References}

[1] Z. Asfari, V. Böhmer, J. Harrowfield, J. Vicens, M. Saadioui (Eds.), Sensor Applications, Kluwer Academic Publishers, Dordrecht, 2002. 
[2] S.K. Kim, J.L. Sessler, Chem. Soc. Rev. 39 (2010) 3784

[3] R. Joseph, C.P. Rao, Chem. Rev. 111 (2011) 4658.

[4] B. Mokhtari, K. Pourabdollah, N. Dalali, J. Inclusion Phenom. Macrocycl. Chem. 69 (2011) 1

[5] C. Gaeta, F. Troisi, C. Talotta, T. Pierro, P. Neri, J. Org. Chem. 77 (2012) 3634

[6] J.-M. Liu, Q.-Y. Zheng, J.-L. Yang, C.-F. Chen, Z.-T. Huang, Tetrahedron Lett. 43 (2002) 9209.

[7] A. Drljaca, M.J. Hardie, C.L. Raston, L. Spiccia, Chem. Eur. J. 5 (1999) 2295.

[8] B. Tabakci, M. Yilmaz, A.D. Beduk, J. Appl. Polym. Sci. 125 (2012) 1012.

[9] C. Huang, J. Ahn, S. Kwon, J. Kim, J. Lee, Y. Han, H. Kim, Appl. Catal., A 258 (2004) 173.

[10] E. Sy Dy, H. Kasai, C. Redshaw, C.J. Pickett, Surf. Interface Anal. 40 (2008) 1092.

[11] Q. Liang, B. Guan, M. Jiang, J. Mater. Chem. 20 (2010) 8236.

[12] M. Liu, W. Liao, C. Hu, S. Du, H. Zhang, Angew. Chem., Int. Ed. 51 (2012) 1585.

[13] B. Mokhtari, K. Pourabdollah, Desalination 292 (2012) 1.

[14] M. Mourer, H. Massimba Dibama, P. Constant, M. Daffé, J.-B. Regnouf-de-Vains, Bioorg. Med. Chem. 20 (2012) 2035.

[15] L. Monnereau, D. Sémeril, D. Matt, Eur. J. Org. Chem. 2012 (2012) 2786.

[16] J. Zeller, S. Koenig, U. Radius, Inorg. Chim. Acta 357 (2004) 1813.

[17] J. Hausmann, M.H. Klingele, V. Lozan, G. Steinfeld, D. Siebert, Y. Journaux, J.J. Girerd, B. Kersting, Chem. Eur. J. 10 (2004) 1716.

[18] A. Bilyk, J.W. Dunlop, A.K. Hall, J.M. Harrowfield, M.W. Hosseini, G.A. Koutsantonis, B.W. Skelton, A.H. White, Eur. J. Inorg. Chem. 2010 (2010) 2089.

[19] A. Bilyk, J.W. Dunlop, R.O. Fuller, A.K. Hall, J.M. Harrowfield, M.W. Hosseini, G.A. Koutsantonis, I.W. Murray, B.W. Skelton, R.L. Stamps, A.H. White, Eur. J. Inorg. Chem. 2010 (2010) 2106.

[20] S.M. Taylor, G. Karotsis, R.D. McIntosh, S. Kennedy, S.J. Teat, C.M. Beavers, W. Wernsdorfer, S. Piligkos, S.J. Dalgarno, E.K. Brechin, Chem. Eur. J. 17 (2011) 7521.

[21] V.C. Gibson, C. Redshaw, W. Clegg, M.R.J. Elsegood, Chem. Commun. (1997) 1605.

[22] M.I. Ogden, B.W. Skelton, A.H. White, J. Chem. Soc., Dalton Trans. (2001) 3073.

[23] C. Redshaw, D. Homden, D.L. Hughes, J.A. Wright, M.R.J. Elsegood, Dalton Trans. (2009) 1231.

[24] Y. Bi, G. Xu, W. Liao, S. Du, X. Wang, R. Deng, H. Zhang, S. Gao, Chem. Commun. 46 (2010) 6362.

[25] S. Sanz, K. Ferreira, R.D. McIntosh, S.J. Dalgarno, E.K. Brechin, Chem. Commun. 47 (2011) 9042

[26] V.V. Yanilkin, A.R. Mustafina, A.S. Stepanov, N.V. Nastapova, G.R. Nasybullina, A.Y. Ziganshina, S.E. Solovieva, A.I. Konovalov, Russ. J. Electrochem. 47 (2011) 1082.

[27] Y. Bi, W. Liao, G. Xu, R. Deng, M. Wang, Z. Wu, S. Gao, H. Zhang, Inorg. Chem. 49 (2010) 7735 .

[28] Y. Bi, X.-T. Wang, W. Liao, X. Wang, R. Deng, H. Zhang, S. Gao, Inorg. Chem. 48 (2009) 11743.

[29] Y. Cheremond, A. Crochet, K.M. Fromm, Eur. J. Inorg. Chem. 16 (2012) 2725.

[30] A. Crochet, K.M. Fromm, Z. Anorg. Allg. Chem. 636 (2010) 1484

[31] A. Crochet, K.M. Fromm, Z. Anorg. Allg. Chem. 637 (2011) 2089.

[32] A. Crochet, E. Kottelat, A. Fleury, M. Neuburger, K.M. Fromm, Z. Anorg. Allg. Chem. 637 (2011) 672.

[33] F. Gschwind, A. Crochet, W. Maudez, K.M. Fromm, Chimia 64 (2010) 299.

[34] F. Gschwind, K.M. Fromm, Z. Anorg. Allg. Chem. 637 (2011) 1871

[35] F. Gschwind, K.M. Fromm, CrystEngComm 14 (2012) 4008.

[36] F. Gschwind, O. Sereda, K.M. Fromm, Inorg. Chem. 48 (2009) 10535.

[37] W. Maudez, T. Vig-Slenters, L. Mirolo, A. Fleury, K.M. Fromm, Main Group Chem. 5 (2006) 41 .

[38] W. Maudez, D. Haeussinger, K.M. Fromm, Z. Anorg. Allg. Chem. 632 (2006) 2295.

[39] K.M. Fromm, Chem. Commun. (1999) 1659.

[40] K.M. Fromm, E.D. Gueneau, H. Goesmann, Chem. Commun. (2000) 2187.
[41] K.M. Fromm, E.D. Gueneau, G. Bernardinelli, H. Goesmann, J. Weber, M.J. Mayor-Lopez, P. Boulet, H. Chermette, J. Am. Chem. Soc. 125 (2003) 3593.

[42] W. Maudez, K.M. Fromm, Helv. Chim. Acta 92 (2009) 2349.

[43] K.M. Fromm, A. Crochet, J.-P. Brog, Lithium Metal Aryloxide Clusters as Starting Products for Oxide Materials, University of Fribourg, Switzerland, 2012.

[44] R.D. Bergougnant, A.Y. Robin, K.M. Fromm, Cryst. Growth Des. 5 (2005) 1691.

[45] R.D. Bergougnant, A.Y. Robin, K.M. Fromm, Tetrahedron 63 (2007) 10751.

[46] E.D. Gueneau, K.M. Fromm, H. Goesmann, Chem. Eur. J. 9 (2003) 509.

[47] W.-G. Wang, Q.-Y. Zheng, Z.-T. Huang, Synth. Commun. 29 (1999) 3711.

[48] G. Guillemot, E. Solari, C. Rizzoli, C. Floriani, Chem. Eur. J. 8 (2002) 2072

[49] S.R. Dubberley, A.J. Blake, P. Mountford, Dalton Trans. (2003) 2418.

[50] S.R. Dubberley, A.J. Blake, P. Mountford, Chem. Commun. (1997) 1603.

[51] J. Hesschenbrouck, E. Solari, C. Floriani, N. Re, C. Rizzoli, A. Chiesi-Villa, Dalton (2000) 191.

[52] L. Giannini, A. Caselli, E. Solari, C. Floriani, A. Chiesi-Villa, C. Rizzoli, N. Re, A. Sgamellotti, J. Am. Chem. Soc. 119 (1997) 9198.

[53] J. Old, A.A. Danopoulos, S. Winston, New J. Chem. 27 (2003) 672.

[54] A.W. Addisson, N.T. Rao, J. Jan Reedijk, J. van Rijn, G.C. Verschoor, J. Chem. Soc., Dalton Trans. (1984) 1349.

[55] A.L. Spek, J. Appl. Crystallogr. 36 (2003) 7.

[56] I.D. Brown, Chem 13 [Thirteen] News 63 (1974) 1.

[57] I.D. Brown, Chem 13 [Thirteen] News 64 (1974) 3.

[58] H. Jiang, X. Pan, L. Huang, J. Zhao, D. Shi, Chem. Commun. (Cambridge, UK) 48 (2012) 4698.

[59] B.B.A.F. Le, M.D. Greenhalgh, S.P. Thomas, Chem. Commun. (Cambridge, UK) 48 (2012) 1580.

[60] Y. Xie, M. Yu, Y. Zhang, Synthesis (2011) 2803.

[61] W. Zhao, J. Yu, S. Song, W. Yang, H. Liu, X. Hao, C. Redshaw, W.-H. Sun, Polymer $53(2012) 130$.

[62] C.W. Lee, D.H. Ahn, B. Wang, J.S. Hwang, S.-E. Park, Microporous Mesoporous Mater. 44-45 (2001) 587.

[63] G. Pecchi, P. Reyes, T. Lopez, R. Gomez, A. Moreno, J.L.G. Fierro, J. Chem. Technol. Biotechnol. 77 (2002) 944.

[64] A. Abu-Surrah, K.A. Ibrahim, M.Y. Abdalla, A.A. Issa, J. Polym. Res. 18 (2011) 59.

[65] M. Giusti, E. Solari, L. Giannini, C. Floriani, A. Chiesi-Villa, C. Rizzoli, Organometallics 16 (1997) 5610.

[66] V. Esposito, E. Solari, C. Floriani, N. Re, C. Rizzoli, A. Chiesi-Villa, Inorg. Chem. 39 (2000) 2604

[67] B. Giese, private communication.

[68] M. Frediani, D. Semeril, A. Comucci, L. Bettucci, P. Frediani, L. Rosi, D. Matt, L. Toupet, W. Kaminsky, Macromol. Chem. Phys. 208 (2007) 938.

[69] U. Radius, Inorg. Chem. 40 (2001) 6637.

[70] M.G. Gradiner, G.A. Koutsantonis, S.M. Lawrence, P.J. Nichols, C.L. Raston, Chem. Commun. (1996) 2035.

[71] L. Salmon, P. Thuery, M. Ephritikhine, Chem. Commun. (2006) 856.

[72] J. Espinas, U. Darbost, J. Pelletier, E. Jeanneau, C. Duchamp, F. Bayard, O. Boyron, J.-P. Broyer, J. Thivolle-Cazat, J.-M. Basset, M. Taoufik, I. Bonnamour, Eur. J. Chem. (2010) 1349.

[73] P.D.J. Grootenhuis, P.A. Kollman, L.C. Groenen, D.N. Reinhoudt, G.J. van Hummel, F. Ugozzoli, G.D. Andreetti, J. Am. Chem. Soc. 112 (1990) 4165.

[74] C. Fischer, T. Gruber, D. Eissmann, W. Seichter, E. Weber, Cryst. Growth Des. 11 (2011) 1989.

[75] C. Fischer, P. Bombicz, W. Seichter, F. Katzsch, E. Weber, Cryst. Growth Des. 12 (2012) 2445.

[76] D.F. Shriver, The Manipulation of Air-Sensitive Compounds, McGraw-Hill Series in Advanced Chemistry, 1969.

[77] A.S. Wills, valist, Program available from: <www.ccp14.ac.uk/>.

[78] J. Cosier, A.M. Glazer, J. Appl. Crystallogr. 19 (1986) 105

[79] E. Blanc, D. Schwarzenbach, H.D. Flack, J. Appl. Crystallogr. 24 (1991) 1035.

[80] G.M. Sheldrick, Acta Crystallogr., Sect. A 64 (2008) 112. 